\title{
DESENVOLVIMENTO DE OBJETOS EDUCACIONAIS: EXPERIMENTOS EM HIDRÁULICA
}

\author{
Oscar Eduardo Patrón Guillermo* \\ Liane Margarida Rockenbach Tarouco ${ }^{* *}$ \\ Luiz Augusto Magalhães Endres
}

\section{Resumo}

Este trabalho objetiva mostrar a necessidade de desenvolver objetos educacionais para o ensino de hidráulica para engenheiros, mais precisamente o desenvolvimento de simuladores virtuais, destacando as vantagens das simulações como complemento à aula tradicional expositiva, assim como o ganho no processo de ensino e aprendizagem dos alunos, expostos a este tipo de material instrucional. Para isto foi elaborado um simulador utilizando o software Flash MX da Macromedia, representando uma prática laboratorial de hidráulica - velocidade em canal. Duas turmas do curso de Engenharia da UFRGS, utilizaram estes objetos educacionais, e diversos fatores do seu uso foi avaliado. Os resultados mostram que o tipo de objeto educacional em questão - a simulação, pode ser uma boa ferramenta no auxílio à aula convencional e que na área da Engenharia deve-se investir tempo e recursos para implementar este tipo de objetos.

Palavras-chave: Objetos educacionais, experimentos em hidráulica, simulações.

\section{DEVELOPMENT OF LEARNING OBJECTS: EXPERIMENTS IN HYDRAULICS}

\begin{abstract}
*Abstract
The objective of this work is to show the need for the development of learning objects for teaching hydraulics for engineers, more specifically the development of virtual simulators, and to enhance their advantages as a complement to the traditional expositive lecture and the improvement in the teaching and learning process of the students that were subjected to this kind of material. For this purpose a simulator representing a practical experiment in hydraulics was created using Flash MX Macromedia. Two groups of the UFRGS Engineering School used this educational tool and several aspects of its use were evaluated. The results show that simulation is a good resource in helping conventional lectures in an engineering school and therefore, time and resources should be used to implement this kind of tool.
\end{abstract}

Key words: learning objects; hydraulic experiment; simulation.

\footnotetext{
* Gerente de Rede IPH - Eng. Especialista em Informática na Educação - CINTED/UFRGS. oepg@iph.ufrgs.br

** Diretora Cinted- Doutorado em Engenharia Elétrica-Sistemas Digitais - USP. liane@penta.ufrgs.br

*** Prof. DHH/IPH - Doutorado em Engenharia Mecânica - UFRGS. endres@iph.ufrgs.br
} 


\section{INTRODUÇÃO}

A proposta deste trabalho foi de proporcionar aos alunos da disciplina Mecânica dos Fluidos II - IPH 01107 da UFRGS, semestre 2005/01, além da realização normal dos experimentos práticos previstos em laboratório de hidráulica, o uso de simulações computacionais destes experimentos, tentando mostrar a necessidade de desenvolver novos objetos de aprendizagem, para o ensino de hidráulica para engenheiros, mais precisamente a utilização de simuladores virtuais, das práticas em laboratórios de hidráulica; destacar suas vantagens como complemento à aula tradicional expositiva, assim como o ganho no processo de ensino aprendizagem dos alunos, expostos a este tipo de material instrucional.

Este trabalho faz parte de um estudo de caso maior, sendo que aqui estará sendo citado parte deste estudo, dando uma ênfase maior no próprio objeto educacional. Em (Patrón et al.,2005)- http://www.cinted.ufrgs.br/renote/ , existe uma abordagem mais ampla no que diz respeita às simulações, salientando nos resultados outros aspectos do estudo.

O desenvolvimento de trabalhos de laboratório de hidráulica, na maneira como é normalmente efetuado e que já fornece bons resultados, exige dos alunos, além da absorção de conhecimentos em sala de aula, que leiam previamente um texto especialmente preparado para reforçar os conteúdos e orientar a prática a ser executada no laboratório. A realização prévia de simulações com auxílio da informática desses experimentos, em muito semelhantes às que serão posteriormente desenvolvidas na realidade do laboratório, permite unir os conteúdos vistos em aula, a leitura do texto (que acompanha o próprio experimento) e o interesse peculiar dos estudantes pelo uso do computador como ferramenta de trabalho.

Embora a simulação desenvolvida para esta disciplina, não tenha o objetivo de substituir a prática no laboratório de hidráulica, é possível supor que, após corrigidos pequenos problemas de forma e conteúdo no primeiro conjunto de resultados obtidos, este objeto de aprendizagem possa ser oferecido a outras pessoas e/ou instituições de ensino interessadas (compartilhamento e reuso do objeto), principalmente para aquelas que não disponham do laboratório de hidráulica físico para trabalhar mas que terão, com o uso do meio computacional e as simulações já otimizadas, possibilidade de visualização de fenômenos em muito facilitada.

\section{MOTIVAÇÃO}

As limitações do ensino público, principalmente financeiras, têm feito com que seja necessário enfrentar alguns problemas que acabam por prejudicar não só o ensino, mas também, o aprendizado de alunos universitários. Uma destas limitações é a falta de recursos para a aquisição e manutenção de laboratórios experimentais, utilizados na fixação dos conceitos teóricos, que na área da Engenharia é muito comum. Este fato tem dificultado o contato dos alunos com as práticas de laboratório já que, segundo (Kleinhappel et al.,2004), os laboratórios experimentais ainda em funcionamento, da área de hidráulica e mecânica dos fluídos, remanescentes de épocas de maiores recursos destinados à educação, encontram-se espalhados entre algumas universidades, aliado a isto as simulações tem se destacado como ótimos objetos de aprendizagem, principalmente na área das engenharias, ou até das ciências exatas.

As simulações podem despertar ou aumentar o interesse dos alunos já que, com o fato de poderem controlar determinadas simulações, é induzida uma aprendizagem 
mais fácil e rápida, o aluno pode ver como se altera o comportamento do modelo em uma variedade de situações e condições.

Segundo (Otoni, 2004), em seu trabalho "O uso de Simuladores e as Estruturas Cognitivas", a simulação dá vida às aulas, fornecendo ferramentas com as quais os estudantes apreciam trabalhar, pois desta maneira aprendem fazendo. Trata-se de uma ferramenta de estudo interativa que ajuda a construir e trabalhar conceitos. O mesmo autor relata que em seus experimentos é possível dar acesso virtual a todos os componentes necessários para criar projetos de qualquer complexidade. Ao contrário dos equipamentos didáticos tradicionais, normalmente não é necessária a aquisição de componentes adicionais como, por exemplo, no caso de uma simulação mecânica real, a compra de um componente de maior custo.

\section{OBJETOS DE APRENDIZAGEM}

Os Objetos Educacionais ou "Learning Objects" são elementos de uma nova metodologia de ensino e aprendizagem baseada no uso do computador e da Internet. Eles são fundamentados na linguagem orientada a objetos, valorizando sua criação e reuso para diversos tipos de situações. É uma tecnologia recente que abre caminhos na educação à distância, e como material de apoio à aula presencial tradicional, trazendo inovações e soluções que pode beneficiar a todos os envolvidos no processo de ensino e aprendizagem.

Objetos de Aprendizagem não precisam ser exclusivamente baseados em tecnologias. Um cronograma instrucional, uma determinada atividade de ensino, um livro, uma apostila, são outros exemplos de Objetos de Aprendizagem que não estão ligados diretamente com tecnologias, entretanto, o termo passou a ser muito utilizado por profissionais que desenvolvem e aplicam novas tecnologias com fins educacionais.

O conceito de objeto de aprendizagem vem recebendo diversas denominações, tais como "learning object", "instructional object", "educational object", "knowledge object", "intelligent object", e "data object" (Gibbons, 2000). Qualquer que seja a denominação empregada, o objetivo praticamente não varia: facilitar a decomposição de sistemas educacionais em módulos relativamente pequenos e potencialmente reutilizáveis. Estes objetos de aprendizagem podem ser utilizados em diversos contextos e meios, como aulas presenciais, cursos online, treinamentos baseados no computador, desenvolvimento de tutoriais, entre outros.

Segundo (Logmire, 2001), as características enfocadas em Objetos de Aprendizado são:

. Flexibilidade: Os objetos de Aprendizado podem ser reutilizados em outros contextos

. Facilidade para atualização: Com a fragmentação do conteúdo em pequenas porções, se torna fácil a localização e atualização de conteúdo.

. Customização: Os objetos são totalmente customizáveis para diferentes cursos e/ou clientes

. Interoperabilidade: O Objeto pode ser utilizado em qualquer plataforma, podendo ser adicionado à uma "biblioteca de Objetos"

. Aumento do valor de um Conhecimento: O Objeto, por ser reutilizado, torna-se melhorado ao longo do tempo

. Indexação e Procura: Possibilidade da criação de um banco de objetos para procura de elementos que possam vir a completar outro conteúdo 
Todas essas características mostram que o modelo Objetos de Aprendizado vem para facilitar e melhorar a qualidade do ensino, proporcionando aos tutores, alunos e administradores diversas ferramentas facilitadoras.

Segundo a norma IEEE 1484 (IEEE, 2002) "um objeto de aprendizagem é definido como qualquer entidade, digital ou não, que possa ser usada para aprendizagem, educação ou treinamento", porém, são os conteúdos potencialmente reutilizáveis em formato digital que vêm justificando o grande interesse pela tecnologia de objetos de aprendizagem, uma vez que o custo de desenvolvimento de conteúdo virtual interativo é bastante expressivo. Pelo acima mencionado então, os simuladores, que são o objeto de estudo deste trabalho podem ser definidos como objetos de aprendizagem ou "learning objects".

\subsection{SIMULADORES}

As recentes tecnologias de base informática abriram novas perspectivas para o ensino e aprendizagem das ciências em geral. Um dos diversos modos de utilização do computador, como as simulações, permitiram a diversificação de estratégias no ensino. O professor dispõe de novas possibilidades para transmitir conteúdos e os alunos dispõem de uma maior variedade de meios para aprender. Os modos de utilização que disponibilizam formas de aprendizagem interativas são particularmente promissores para aprender ciências.

A simulação é um recurso de aprendizagem que permite ao estudante observar o comportamento de um determinado sistema através de um modelo do mesmo, ou seja, de uma representação matemática, gráfica ou simbólica de um fenômeno. Neste contexto, as simulações podem exercer um papel minimizador do problema existente devido à falta de estrutura de parte das Faculdades de Engenharia do Brasil, em termos de laboratórios e equipamentos, para os cursos de graduação.

Como a simulação realizada para o estudo de caso deste trabalho, foi elaborada com a utilização do software Flash MX, cabe destacar que as simulações em Flash tem algumas vantagens, destacadas a seguir:

- Velocidade. As simulações, desde que bem elaboradas, são tão rápidas quanto de outros programas.

- Acessibilidade. O fato das simulações em Flash não necessitarem de qualquer instalação no computador torna-as de fácil acesso, pois pode-se gerar animações auto-executáveis, ou simplesmente para visualização via Internet, com a simples adição do "plugin" Flash da Macromedia.

- Interação. O Flash permite utilizar um conjunto de elementos gráficos, que permitem interação fácil entre o usuário e a simulação.

- Operacionalidade. Estas simulações podem ligar-se a vários formatos de mídia (texto, gráficos, animação e som, entre outros).

- Portabilidade e usabilidade. Estas animações podem ser salvas como arquivos executáveis, ou até em formatos facilmente importados para páginas Web ou arquivos html, podendo assim desta maneira, disponibilizar o conteúdo das simulações na Internet.

- Recursos de programação. Com a ajuda da linguagem de programação Action Script, pode-se desenvolver novas funcionalidades, e acrescentar recursos sofisticados em termos de animação, e de recursos de cálculo cientifico e utilização de variáveis. 


\section{MATERIAL E MÉTODOS}

Neste trabalho será realizada uma descrição sucinta e objetiva do próprio objeto educacional, uma descrição mais completa e abrangente é localizada em (Patrón et al.,2005) , apresentado em Maio de 2005 no IV Ciclo de Palestras Novas Tecnologias na Educação.

A simulação descrita neste trabalho, foi desenvolvida utilizando o software Flash MX, da Macromedia, e aplicada a uma turma da disciplina regular do curso de Engenharia da UFRGS - Mecânica dos Fluidos II - IPH 01107, semestre 2005/01; esta disciplina fornece conteúdos básicos para o estudo da Hidráulica, Fenômenos de Transporte, Hidrologia, Máquinas Hidráulicas, Saneamento e Gerenciamento de Recursos Hídricos.

Para isto foi elaborado um simulador, representando uma prática laboratorial de hidráulica: Velocidade em Canal. Estas aulas no laboratório de hidráulica, funcionam como uma aplicação prática do conteúdo ministrado na disciplina e vão de encontro ao objetivo da mesma, que são os de fornecer aos alunos os conhecimentos básicos das propriedades dos fluidos, dos esforços mecânicos e das leis de conservação de massa, quantidade de movimento e energia, além de apresentar noções e conceitos básicos do escoamento real.

As figuras a seguir mostram as diferentes seções ou módulos do simulador onde podem ser efetuadas diversas interações com o mesmo, desde a visualização de vídeos e fotos do experimento, visualização da apostila da disciplina, perguntas e testes, até o experimento propriamente dito.

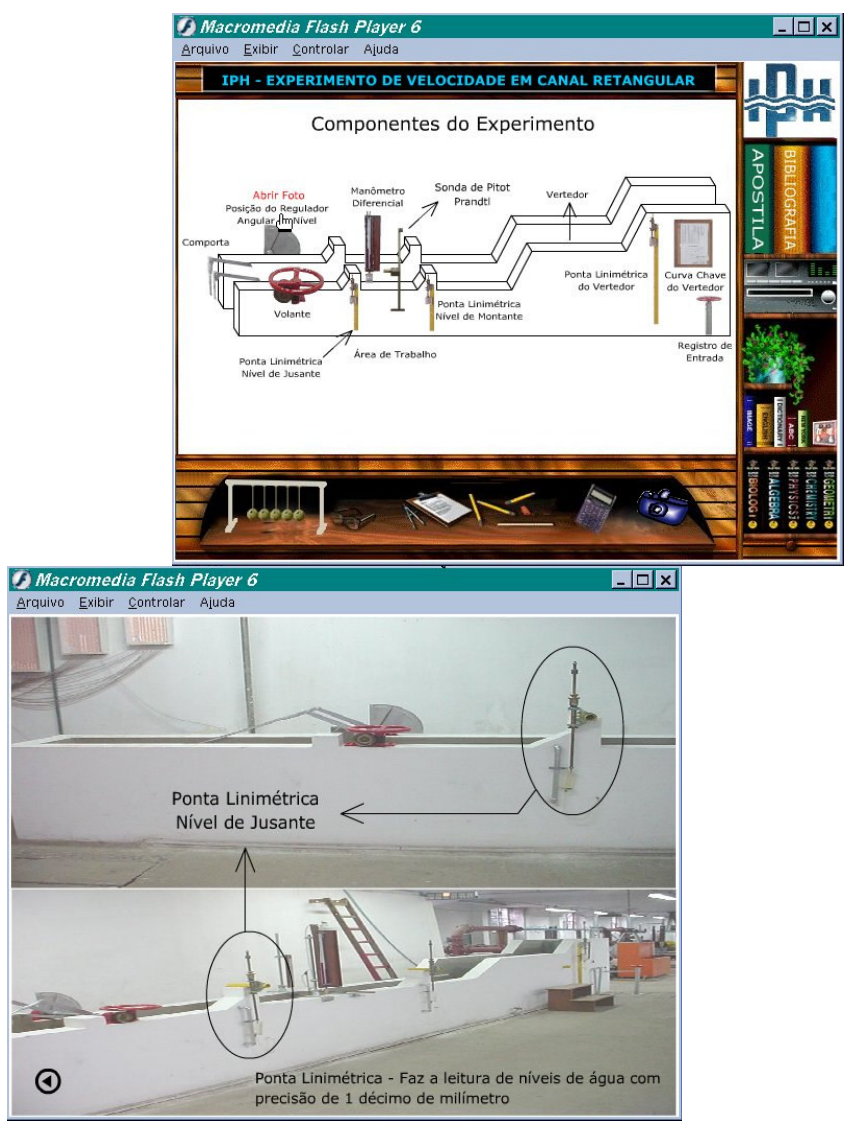

Figura 1. Tela principal do simulador mostrando os componentes do experimento 

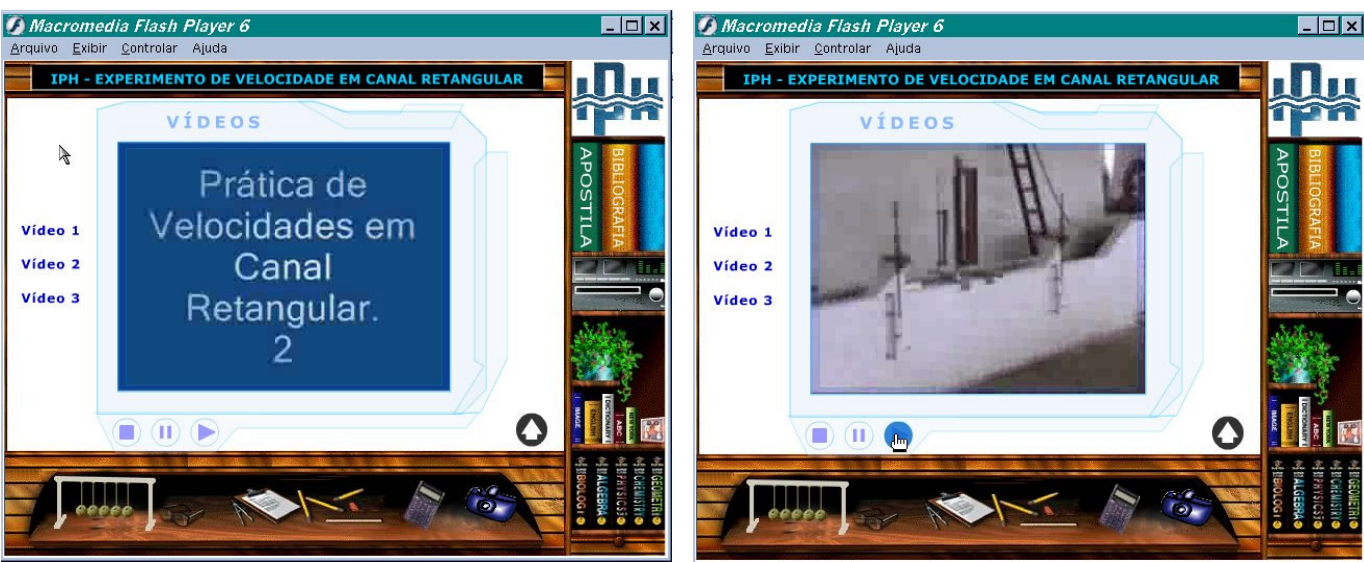

Figura 2. Seção de vídeos do experimento
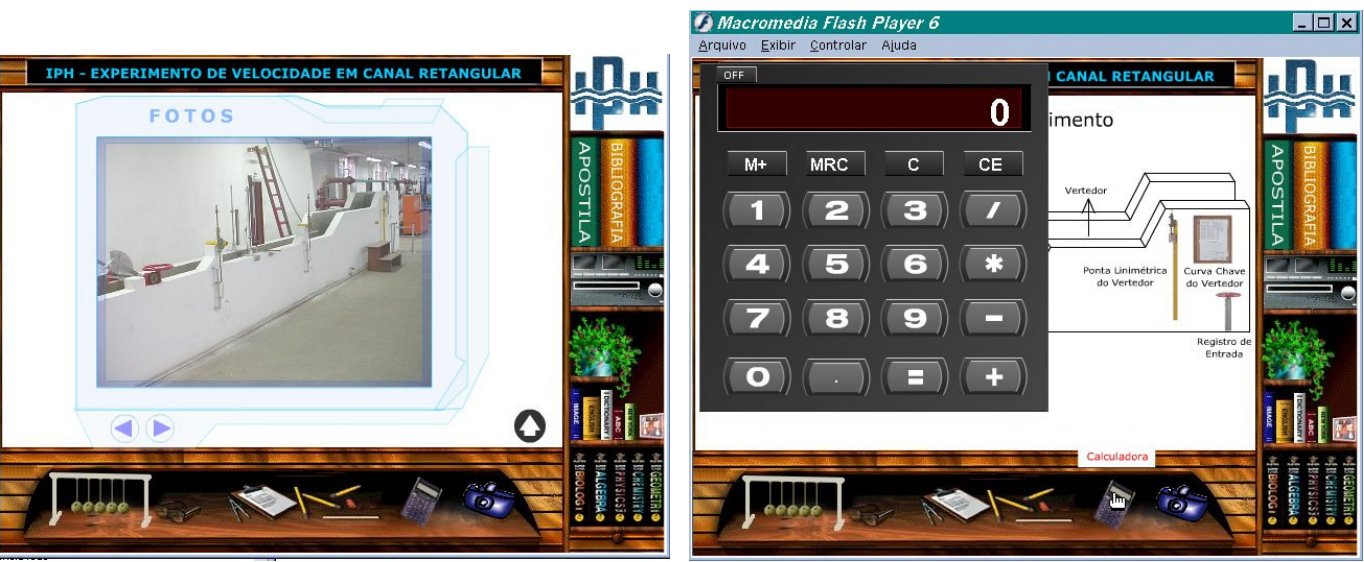

Figura 3. Seção Fotos do experimento e Calculadora
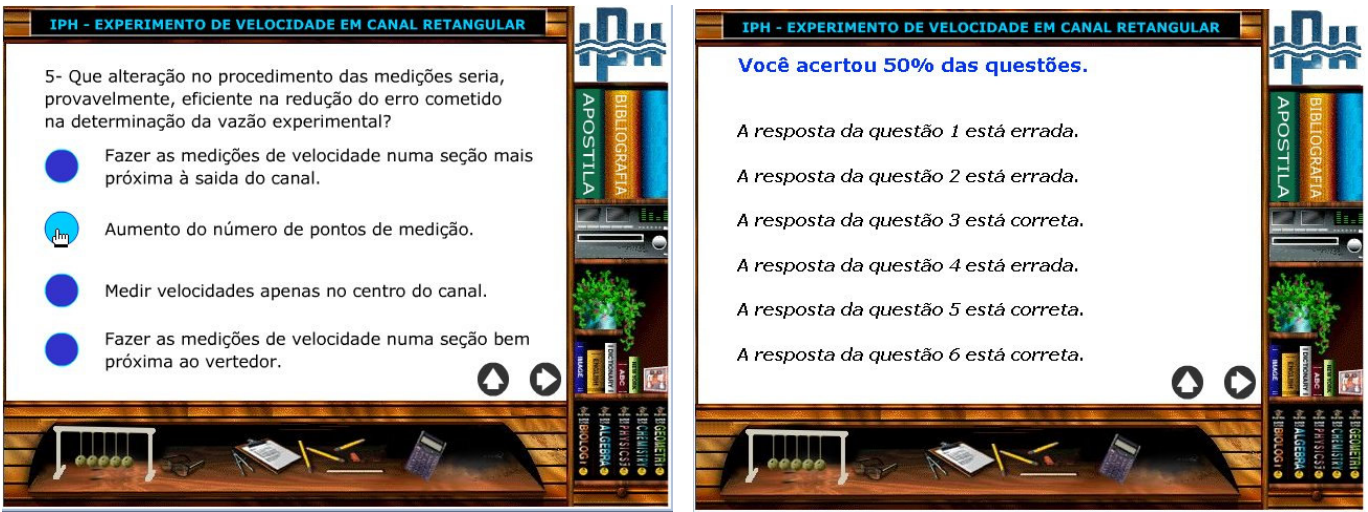

Figura 4. Seção Testes e Perguntas

A seção testes e perguntas é composta por 7 questões, sendo que ao final das mesmas o sistema mostra as índice de acertos e indica as questões certas ou erradas. A seqüência de imagens contida na figura 5, mostra o experimento de simulação propriamente dito, indicando suas fases no seguimento do experimento, havendo uma interação com o usuário, que deverá fazer escolhas para posterior cálculo do simulador. 


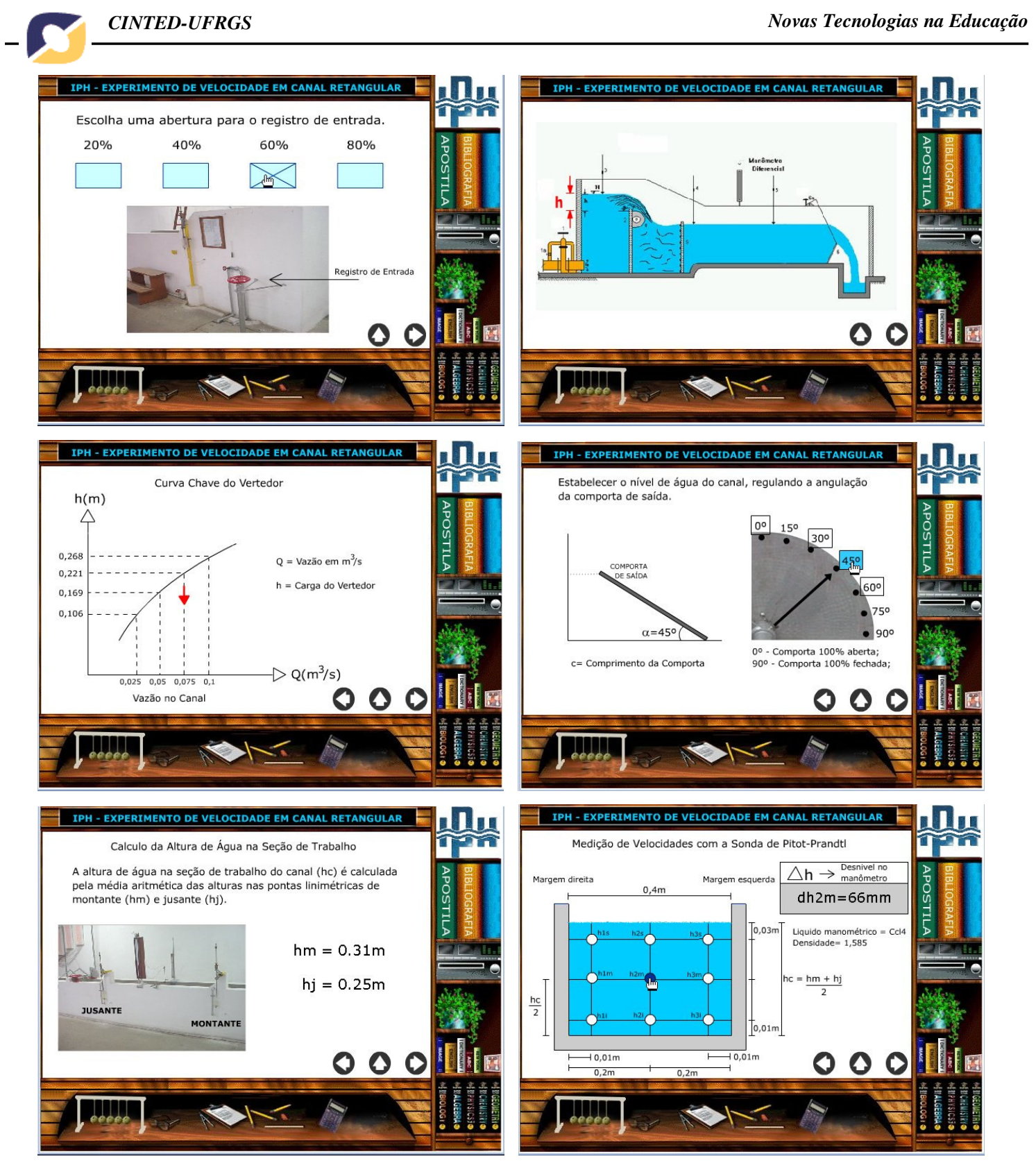

Figura 5. Seqüência de imagens da Seção Experimento

Após todos terem efetuado as aulas práticas (Laboratório de Hidráulica e Sala Informatizada com os simuladores), os alunos responderam a um questionário de avaliação do material instrucional, composto de 30 perguntas, das quais parte delas são avaliadas neste artigo. Destaca-se que desde 2004 vem sendo avaliados simuladores com turmas da Engenharia no IPH, e computando o resultado deste questionário de todas as turmas.

\section{RESULTADOS OBTIDOS}

Os resultados das respostas dos alunos, são analisados em termos percentuais, porém são apresentados também em relação ao número de alunos que responderam às opções fornecidas. A turma Hidra-inf estava composta de 12 alunos e a turma InfHidra era composta de 17 alunos. Foi calculado o percentual de respostas dadas a cada opção, em relação ao número de alunos de cada turma, e após, apresentado em termos médios das 2 turmas. As tabelas aqui apresentadas, foram extraídas da monografia de conclusão do curso de Especialização em Informática na Educação - ESPIE 2004: “O 
Poder das Simulações no Ensino de Hidráulica para Engenheiros”, de mesma autoria deste artigo.

Tabela 1. Importância do apoio multimídia na hidráulica

Quão importante para você é ser exposto a uma ferramenta de apoio multimídia como um simulador, na área de hidráulica?
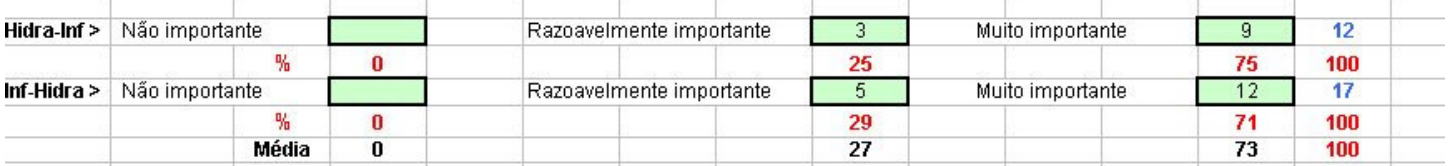

Em média nas 2 turmas, $27 \%$ dos alunos disseram que o simulador foi razoavelmente importante, como ferramenta de apoio, e $73 \%$ afirmaram que é muito importante o uso deste tipo de simulador, tendo sido pouco significativa a diferença entre as turmas

Tabela 2. Profundidade do conteúdo do simulador

A profundidade do conteúdo abrangidłneste simulador foi:

\begin{tabular}{|c|c|c|c|c|c|c|c|}
\hline \multirow[t]{2}{*}{ Hidra-Inf > } & Nẫo suficiente & & A quantia certa & 11 & Demasiado & 1 & 12 \\
\hline & $\%$ & 0 & & 92 & & 8 & 100 \\
\hline Inf-Hidra > & Nẫo suficiente & & A quantia certa & 15 & Demasiado & 2 & 17 \\
\hline & $\%$ & $\mathbf{0}$ & & 88 & & 12 & 100 \\
\hline & Média & $\mathbf{0}$ & & 90 & & 10 & 100 \\
\hline
\end{tabular}

Comparado à "Prática Tradicional" ?

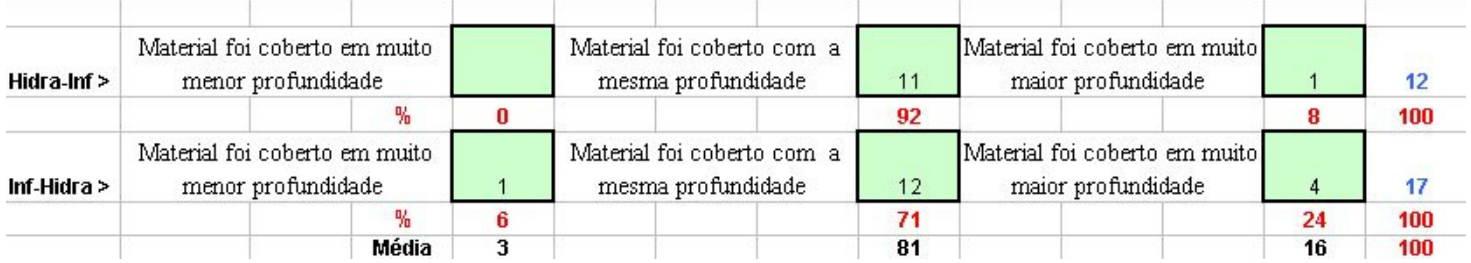

Em média nas 2 turmas, $90 \%$ dos alunos disseram que o conteúdo abrangido no simulador foi a quantia certa, e $10 \%$ disseram ter sido demasiado, porém comparado à prática tradicional, 3\% disseram que o material foi coberto em menor profundidade, $81 \%$ que foi coberto com a mesma profundidade e $16 \%$ dos alunos afirmaram que o material foi coberto em muito maior profundidade.

Tabela 3. Avaliação comparativa do material de apoio

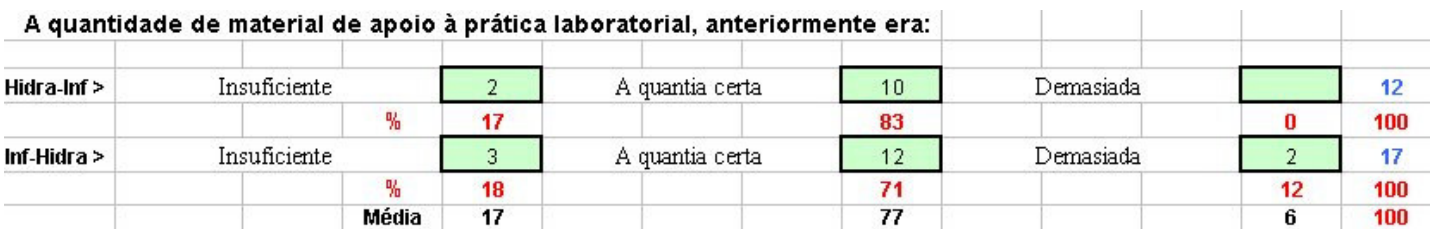

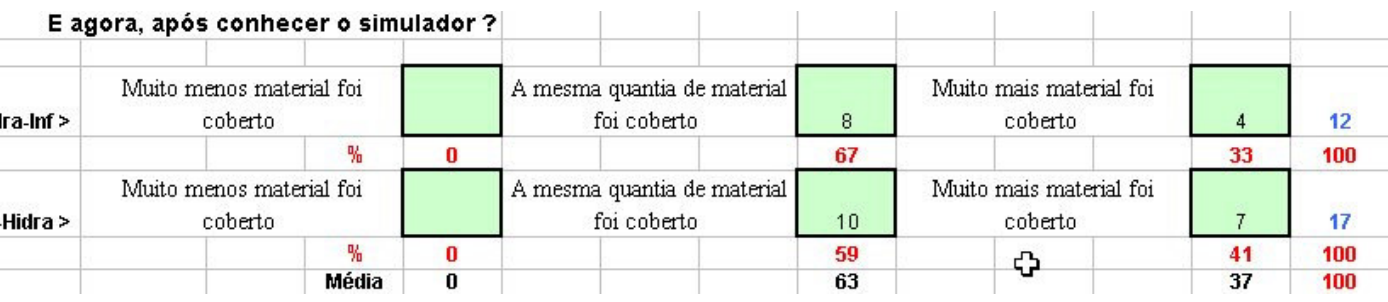


Em média nas 2 turmas, $17 \%$ dos alunos disseram ter achado o material de apoio à prática laboratorial, que anteriormente era dado, como insuficiente, $71 \%$ a quantidade certa e somente $6 \%$ acharam o material demasiado. Após a introdução do simulador como material de apoio, 63\% dos alunos afirmaram que a mesma quantidade de material foi coberto, e $37 \%$ afirmaram que muito mais material foi coberto.

Tabela 4. Importância do aprendizado com o simulador

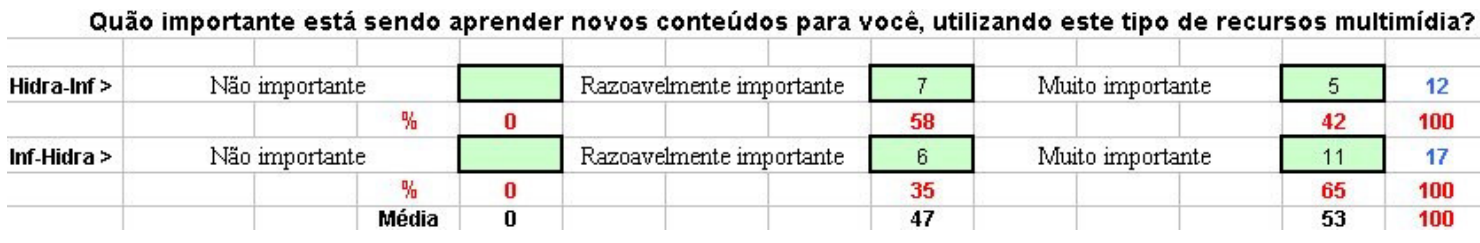

Em média nas 2 turmas, $47 \%$ dos alunos disseram ser razoavelmente importante, utilizar este tipo de recursos, tais como as simulações no ensino, enquanto que 53\% informaram que é muito mais importante aprender novos conteúdos, utilizando este tipo de recursos multimídia. Considerando individualmente as 2 turmas, constata-se que a turma Inf-Hidra, achou muito importante (65\% dos alunos) aprender novos conteúdos com este tipo de material, enquanto que a turma Hidra-Inf achou muito importante em $42 \%$ dos alunos.

Tabela 5. Nível de satisfação no aprendizado com o simulador

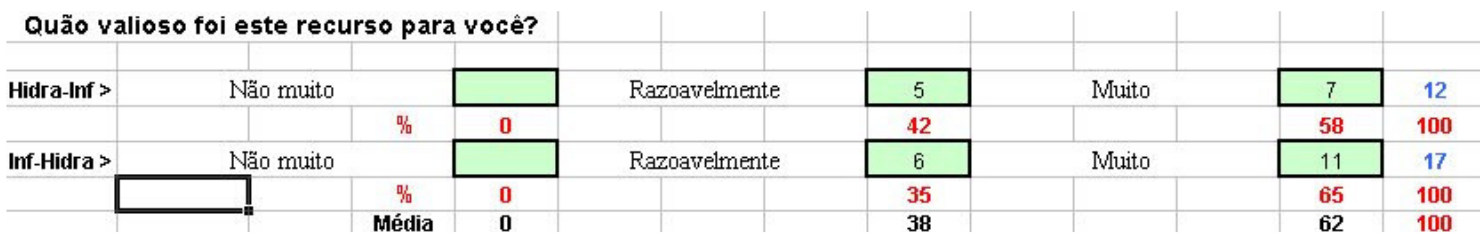

Quando questionados quanto à valia deste recurso, 62\% afirmaram ser $\underline{\text { muito }}$ valioso e $38 \%$ acharam razoavelmente valioso.

Tabela 6. Recomendação para aperfeiçoamento e uso de simuladores

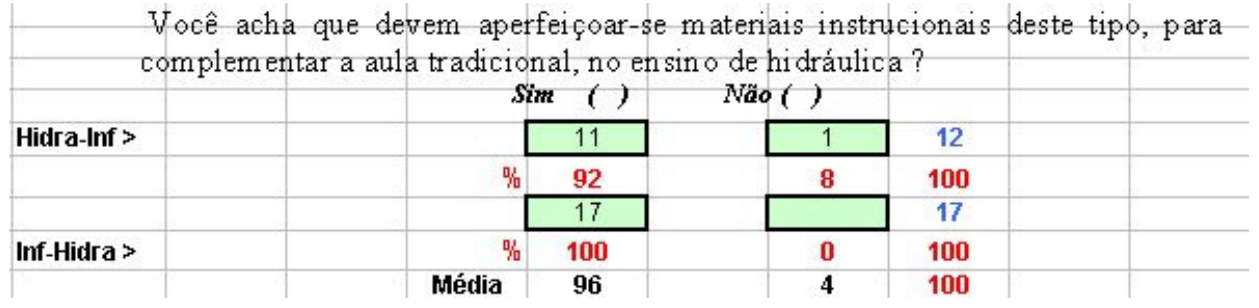

Quando questionados os alunos, quanto a se deviam aperfeiçoar-se materiais instrucionais deste tipo, para complementar a aula de hidráulica, em média $96 \%$ dos alunos disseram que precisa-se elaborar mais materiais deste tipo, sendo que 4\% (representando um único aluno) disse que não vê necessidade de elaborar matérias de apoio multimídia.

Tabela 7. Recomendação para uso de simulações 


\begin{tabular}{|c|c|c|c|c|c|c|c|c|}
\hline \multicolumn{9}{|c|}{ experiência com simuladores de algum tipo, para representar e testar situações } \\
\hline \multicolumn{9}{|c|}{ reais, como práticas de laboratório? } \\
\hline & & & $\operatorname{Sim}()$ & Nâ ( ) & & & & \\
\hline \multirow[t]{2}{*}{ Hidra-Inf s } & & & 12 & & 12 & & & \\
\hline & & $\%$ & 100 & 0 & 100 & & & \\
\hline \multirow[t]{3}{*}{ Imf-Hidra ? } & & & 17 & & 17 & & & \\
\hline & & $\%$ & 100 & 0 & 100 & & & \\
\hline & & Média & 100 & $\mathbf{0}$ & 100 & & & \\
\hline
\end{tabular}

Considerando agora, quando os alunos foram questionados sobre se recomendariam, que outros alunos tivessem o mesmo tipo de experiência com simuladores, semelhante ao ocorrido nas práticas de hidráulica, $100 \%$ dos alunos manifestaram que sim, recomendariam esta experiência.

Tabela 8. Capacidade de execução da prática laboratorial

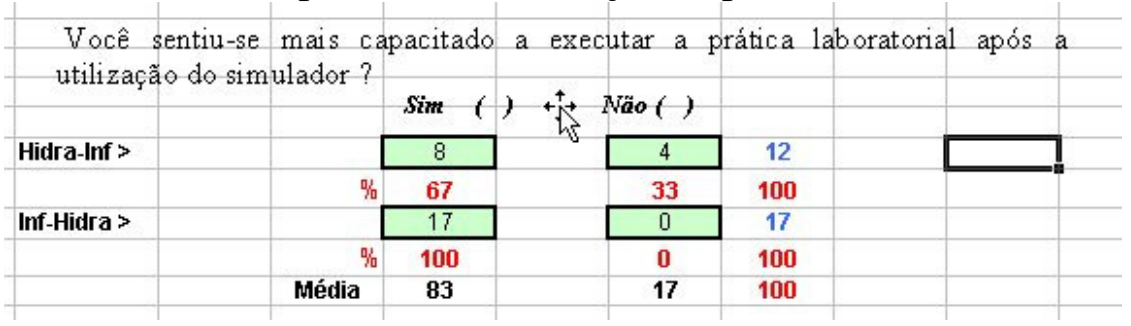

Os alunos foram questionados, sobre se sentiam-se mais capacitados a executar a prática laboratorial, após a utilização do simulador, sendo que somente a turma InfHidra poderia responder, já que somente esta turma efetuou anteriormente a prática com o simulador, interpretando neste caso que os alunos devem ter entendido a pergunta como: "Você sentiria-se mais capacitado ...", pelo fato de terem respondido.

Avaliando os alunos que fizeram primeiramente a prática no laboratório de informática, $100 \%$ deles manifestaram que sentiram-se mais capacitados a executar a prática no laboratório de hidráulica após as simulações, sendo que 33\% dos alunos da outra turma, disseram que não sentiram-se mais capacitados, efetuando antes as simulações, contra $67 \%$ que manifestou sentir-se mais capacitado a realizar a prática após as simulações.

\section{CONCLUSÃO}

O ambiente dentro da sala de aula informatizada, foi muito propício e aberto para a discussão e o debate, sobre as inovações tecnológicas no ensino, principalmente pela postura dos alunos perante a utilização das simulações, destacando que uma ampla maioria (96\%) manifestou de que deveriam ser desenvolvidos mais objetos educacionais deste tipo, para enriquecer as aulas de hidráulica.

Nos questionamentos, na hora de atribuir notas maiores, nos quesitos de maior peso dentro da mesma questão, a turma Inf-Hidra, mostrou-se mais receptiva a avaliar melhor as simulações.

O estudo de caso aqui apresentado demonstrou que as simulações são um ótimo complemento das aulas laboratoriais de hidráulica, permitindo aos alunos efetuarem os experimentos repetidamente, inclusive em suas residências, refletindo mais e melhor sobre os fenômenos investigados. Além disso, o ambiente dentro da sala de aula informatizada, foi muito propício e aberto para a discussão e debate sobre as inovações 
tecnológicas no ensino, principalmente pela postura dos alunos perante a utilização das simulações.

De maneira geral, toda a turma mostrou-se receptiva às simulações, com melhor aproveitamento por parte da turma Inf-Hidra. No entanto, não é possível afirmar, com os resultados até aqui levantados, se a ordem ideal é realizar antes as simulações do que a prática convencional. Novas experiências e avaliação de questionários com novas turmas talvez possam indicar este caminho. Na continuidade deste processo está sendo analisada a receptividade de várias turmas a estas ferramentas, o que poderá permitir confirmações e conclusões mais abrangentes sobre o efeito que as simulações têm sobre o processo de ensino-aprendizagem dos alunos da Engenharia.

Para a elaboração das simulações deverá existir uma equipe multidisciplinar abrangendo a área técnica do assunto em questão, a área pedagógica educacional e a área técnica da linguagem de desenvolvimento da simulação, em um ambiente de interação e colaboração entre os envolvidos.

Por fim deve-se ressaltar que, além de servir como um ótimo material de apoio ou complemento da aula prática, para aquelas Instituições que dispõem de recursos laboratoriais, o uso das simulações poderá ser também, excelente para aquelas Instituições que não dispõem destes recursos. A utilização das simulações em aulas práticas informatizadas, seria uma primeira aproximação para os alunos na avaliação dos fenômenos físicos estudados, contribuindo de maneira significativa para a qualidade do ensino como um todo.

\section{REFERÊNCIAS BIBLIOGRÁFICAS}

EDWARD, N. An evaluation of student perceptions of screen presentations in computer-based laboratory simulations. European Journal of Engineering Education, Oxfordshire, v. 22, n. 2, p. 143-151, June, 1997.

GIBBONS, A. S.; Nelson; J. The Nature and Origin of Instructional Objects. Utah State University, 2000. In: Wiley, D.A. (Ed.) The Instructional Use of Learning Objects: Online Version. Disponível em: http://reusability.org/read/chapters/gibbons.doc Acesso em 16/11/2004.

IEEE IEEE Standard for Learning Object Metadata (IEEE Std 1484.12.1TM - 2002). New York, IEEE, 2002.

LONGMIRE, W. A Primer On Learning Objects. American Society for Training \& Development. Virginia. USA. 2001.

MICROSOFT. Entrevista com César Nunes. Objetos de aprendizagem a serviço do professor.http://www.microsoft.com/brasil/educacao/parceiro/objeto_texto.mspx. Acessado em 25/08/2005.

MATEUS, Caroline Melissa Kleinhappel; PALHARES, Juliana Barbosa; LUViZOTTO Júnior, Edevar. Laboratório virtual de mecânica do fluidos. In: Congresso Latinoamericano de Hidráulica, 2004., São Paulo. São Paulo: UNICAMP.

OTONI, Luis. Educação Tecnológica - O uso de Simuladores e as Estruturas Cognitivas. PGIE/UFRGS e CEFET-RS. Disponível em: http://cmi.cefetrs.tche.br/ ribeiro/teste.htm - Acessado em 29/12/2004. 
PATRÓN Guillermo, Oscar E.; TAROUCO Rockenbach, Liane M.; ENDRES Magalhães, Luiz A. O Poder das Simulações no Ensino de Hidráulica. RENOTE Revista Novas Tecnologias na Educação, Porto Alegre, v. 3, n. 1, maio, 2005. 